\title{
Implementing Surviving Sepsis guidelines in a district general hospital
}

\author{
${ }^{1}$ I Page, ${ }^{2} \mathrm{G}$ Hardy, ${ }^{3} \mathrm{~J}$ Fairfield, ${ }^{4} \mathrm{D}$ Orr, ${ }^{5} \mathrm{R}$ Nichani \\ ${ }^{1}$ ST5 Specialty Registrar in Infectious Diseases, North Manchester General Hospital, Manchester, UK; ${ }^{2}$ CT3 Emergency Medicine, Preston \\ Royal Hospital, Preston, UK; ${ }^{3}$ Medical Student, The University of Manchester, Manchester, UK; ${ }^{4}$ Microbiology Consultant, Preston Royal \\ Hospital, Preston, UK; ${ }^{5}$ Intensive Care Consultant, Blackpool Victoria Hospital, Blackpool, UK
}

\begin{abstract}
We describe efforts made at Blackpool Victoria Hospital to implement the well-established international Surviving Sepsis guidelines. These included posters, pocket guides and stickers inserted in patient notes. All doctors and nurses in acute areas received specific information and education. Sepsis teams comprising both doctors and nurses were formed to encourage implementation and to audit and disseminate data. Data collection occurred from February to November 2009. Cases were considered prospectively at the time of initial assessment and 198 patients were identified; 169 (85\%) had blood cultures taken; I 46 (74\%) had lactate levels measured; and I 45 (74\%) received antibiotics within the target time. We believe these results demonstrate relatively effective implementation of guidelines in the challenging environment of a district general hospital. Our results could be replicated easily and provide a good way of reducing patient mortality at minimal financial cost.
\end{abstract}

KEYWORDS Infection, care systems, guidelines, sepsis
Correspondence to I Page, Flat 21, 79 Piccadilly, Manchester, MI 2BU, UK

tel. +44 (0)7974805378 e-mail iainpage9@hotmail.com

DECLARATION OF INTERESTS No conflicts of interest declared.

\section{INTRODUCTION}

Sepsis is a complex syndrome, difficult to diagnose and treat appropriately. Severe sepsis has a very high mortality rate in comparison with other acute medical conditions, around $30-50 \%$ at three to six months. ${ }^{1-3}$ This level ranks alongside lung, breast and colon cancer mortality rates. It is also one of the leading causes of admission to the intensive care unit (ICU). ${ }^{46}$

In 2002 the Surviving Sepsis Campaign was established. It was a joint venture between the European Society of Intensive Care Medicine, the International Sepsis Forum and the Society of Critical Care Medicine. The goal of the campaign was to review all of the evidence relating to sepsis management and provide an internationally accepted consensus position on the issue. This resulted in the publication in 2004 of the surviving sepsis campaign guidelines for the management of severe sepsis and septic shock.' This provided for the first time a universally accepted definition of sepsis to aid clinicians in the recognition and management of sepsis. These guidelines were reviewed in $2008^{8}$ with the representation and agreement of 27 different medical organisations from around the world.

These guidelines define sepsis as the presence of Systemic Inflammatory Response Syndrome (SIRS) plus infection. Systemic Inflammatory Response Syndrome is defined as two or more of the following five factors: temperature $>38.5^{\circ} \mathrm{C}$ or $<36.0^{\circ} \mathrm{C}$; heart rate of $>90$ beats/minute; respiratory rate of $>20$ breaths/minute; white blood cell count of $>12,000$ cells $/ \mathrm{ml}$ or $<4000$ cells $/ \mathrm{ml}$; blood glucose $>7.7 \mathrm{mmol} / \mathrm{L}$ in the absence of diabetes. Severe sepsis is defined as sepsis plus evidence of hypoperfusion or end-organ dysfunction. There are many indicators for severe sepsis, but key indicators are systolic blood pressure (BP) $<90 \mathrm{mmHg}$, serum lactate $>4 \mu \mathrm{mol} / \mathrm{L}$ or acute renal impairment (Figure 2).

These signs may seem non-specific and can apply to a substantial proportion of patients admitted during a general medical intake. If patients with sepsis are not identified and treated early however, they can progress to severe sepsis with the corresponding high risk of mortality. Each hour delay in providing antibiotics and fluids increases the risk.

Surviving Sepsis guidelines therefore advocate the implementation of the following 'bundle' of interventions for all patients with severe sepsis within the first six hours of admission: 1) Measure serum lactate. 2) Obtain blood cultures prior to antibiotic administration. 3) Administer broad-spectrum antibiotics within three hours of admission to the emergency department (or one hour of admission elsewhere). 4) Administer IV fluid bolus if hypotension or raised lactate present. 5) Insert a central venous catheter and achieve a central venous pressure (CVP) of $>8 \mathrm{mmHg}$ and a central venous oxygen saturation of $>70 \%$ for those with persisting hypotension or a raised lactate level after fluid bolus. 6) Apply vasopressors if hypotension or a raised lactate persists despite fluid resuscitation. It should be noted that while blood cultures, antibiotics and lactate measurement are needed in all patients, 
aggressive fluid resuscitation is indicated only when there is evidence of tissue hypoperfusion. Even then there may be some circumstances where it is not appropriate (e.g. comorbidities such as heart failure) and these guidelines are not intended to be a substitute for clinical judgement.

The identification of patients with SIRS early enough to meet the one hour antibiotic target was predicted to be the key challenge in implementing these guidelines effectively. In common with most admitting units in the UK, our department is led by senior staff who are available to lead care of sick patients 24 hours a day. It is nurses however, who perform the initial triage of patients and often junior doctors who are the first to assess new patients. In order to effectively implement the severe sepsis guidelines, we aimed to identify SIRS at the initial nurse led triage, and ensure that all patients with SIRS were assessed immediately for signs of severe sepsis. Once identified, we wanted to ensure that the first three stages of intervention (measuring lactate levels, taking blood cultures and administering antibiotics) were implemented in all septic patients. The Surviving Sepsis guidelines only apply to severe sepsis, but we wanted to identify all cases of sepsis in order to reduce the number of progressions to organ dysfunction through early intervention.

Our aim was to make SIRS assessment a routine part of care in all acute medical admissions in the expectation that this would lead to high levels of effective and appropriate treatment. We set up a dedicated sepsis team to lead a high profile education campaign available to all staff in these departments. We also introduced 'sepsis leads' among both medical and nursing staff to encourage implementation. New working practices were also introduced to ensure prioritisation of the medical assessment of septic patients and to make it easy for doctors to access and implement the guidelines when sepsis was identified. We then recorded our compliance with the guidelines for patients we identified as septic.

\section{METHODS}

Our campaign took place in Blackpool Victoria Hospital, a district general hospital in the north west of England which admits around 14,000 acute adult patients a year. We set up a Surviving Sepsis team in 2009 consisting primarily of a critical care consultant (the overall clinical lead), an ICU outreach nurse, a CTI trainee on the acute common care stem and an ST4 trainee in infectious diseases and general medicine. Each team member had a pre-existing full-time post and our clinical commitments remained unchanged. Membership of the team was voluntary and there was no financial reward. The Trust provided funding for posters and information cards.
We launched the programme in the emergency medicine department and the clinical decisions unit (CDU). We hoped that good practice established in these areas would spread to the rest of the hospital as most doctors either rotate through there or review patients there. Active support was sought and obtained from senior consultants and nursing staff within these areas before the campaign was launched. A lead sepsis nurse was appointed from the full-time staff of each department.

Our aim was to assess all patients for SIRS at the time of triage. A doctor would then see patients with SIRS immediately. This would be facilitated by the use of a 'red dot' system on the admissions board (i.e. any septic patient was marked with a red dot and became the next person to be assessed by a doctor). The doctor would begin following the first stages of intervention according to the sepsis pathway if he felt the diagnosis of sepsis was correct. A Surviving Sepsis sticker (Figure I) was placed in the patient's notes, which provided a flow chart to guide management and also acted as an audit tool as each task was to be ticked when complete. If a doctor felt a particular step in the pathway was inappropriate in a particular patient they were free to exercise clinical judgement, but were required to document the reason for not implementing the protocol.

An education campaign was introduced to motivate staff to implement the guidelines. A grand round presentation was performed. In addition, lectures on sepsis were given to all junior doctors in the Trust both at induction stage and again at a later point in the teaching programme. All nurses in the departments were given small-group tutorials; lectures were not practical due to shift patterns. All junior doctors were given pocket cards detailing the guidelines, and posters (Figure 2) were placed in prominent places in the departments. Staff were frequently updated on progress through departmental audit meetings and regular feedback was given.

Stickers placed in patient's notes used tick boxes to act as an audit trail. These were filled in by the staff during the course of the patients' treatment. The data gathered on these stickers between February and July 2009 were later compiled. It should be noted that any patient in the Accident \& Emergency (A\&E) department found to be septic is included as an A\&E patient, even though some might have moved to CDU during the first six hours of care. Patients where sepsis was identified while in CDU and the sticker was inserted in the notes in CDU are noted as CDU patients. This includes both direct GP admissions and patients who were transferred from A\&E, where sepsis was recognised after arrival in CDU.Timings for compliance with the guidelines are taken from the time of arrival in $C D U$, regardless of whether they arrived directly from a GP or were transferred from A\&E. 


\section{INSERT THIS STICKER IN NOTES of ALL septic patients SEPSIS = 2 X SIRS criteria PLUS INFECTION \\ SEPSIS PATHWAY}

This sticker is an abbreviated version of guidelines. When bundle fully implemented mortality is $25 \%$ less. Some aspects may be inappropriate for some patients - exercise clinical judgement. When bundle complete continue standard care and monitoring for deterioration.

NAME:

UNIT NO:

DATE: TIME ADMITTED TO CDU:

Give oxygen, commence effective fluid balance monitoring - consider catheterisation

Has lactate been measured

Yes $\quad \square \quad$ No

Have blood cultures been taken?

Yes $\quad \square \quad$ No

Have antibiotics been ADMINISTERED within 3 hours of arrival in A\&E?

Yes $\square \quad$ No

Are any of the following severe sepsis criteria present and new to the $\mathrm{pt}$ ?

Systolic BP $<90$ / sats $<90 \%$ on air / creat $>177$ / plats $<100$ / bilirubin $>34$ / INR $>1.5$ / altered mental state

Yes $\quad \square \quad$ No $\quad \square \quad \Rightarrow$ Severe sepsis not present $=>$ antibiotics and routine medical care

Is systolic $\mathrm{BP}<90 \mathrm{mmHg}$ OR lactate $>4$ ?

$$
\text { Yes } \quad \square \quad \text { No } \quad \square \quad \text { => Sepsis Bundle now complete. }
$$

Has a fluid challenge of $20 \mathrm{ml} / \mathrm{kg}$ been ADMINISTERED?

$$
\text { Yes } \square \quad \text { No }
$$

Is systolic BP $<90 \mathrm{mmHg}$ or lactate $>4$ post fluid challenge?

$$
\text { Yes } \quad \square \text { No } \quad \square \quad \text { => Surviving Sepsis bundle now complete }
$$

Has a central line been inserted?

$$
\text { Yes } \quad \square \quad \text { No }
$$

Achieve CVP of $8-12 \mathrm{mmHg}$. Is systolic BP still $<90 \mathrm{mmHg}$ or Lactate $>4.0$ ?

Yes $\square$ No $\quad \square \quad=$ Surviving Sepsis Bundle now complete

Has the Patient been referred to ICU?

Yes $\quad \square \quad$ No $\quad \square \quad$ => Surviving Sepsis Bundle now complete

\section{ALL PATIENTS - HAS WHOLE BUNDLE BEEN COMPLETED WITHIN 6 HOURS OF ADMISSION} Yes $\square \quad$ No

Record any reasons for deviation from protocol below

In June 2011 the nearby Preston Royal Hospital conducted a retrospective audit of patients treated with tazocin, who were found to meet the SIRS criteria at the time of antibiotic initiation. The most common indication for tazocin use in this hospital is treatment of presumed sepsis of unknown source. This method would not have been expected to identify all patients with sepsis. It should, however provide a representative sample for gathering information regarding sepsis guideline compliance. The results of this audit are included for comparison.

\section{RESULTS}

In the CDU, 75 patients were identified with sepsis, and of these, $56(75 \%)$ had blood cultures taken, 42 (56\%) 
TABLE I Results for all patients with sepsis

\begin{tabular}{|l|l|l|l|l|}
\hline & $\begin{array}{l}\text { Blood } \\
\text { cultures } \\
\text { taken }\end{array}$ & $\begin{array}{l}\text { Lactate } \\
\text { levels } \\
\text { measured }\end{array}$ & $\begin{array}{l}\text { Time } \\
\text { to anti- } \\
\text { biotics }\end{array}$ & $\begin{array}{l}\text { Compliance } \\
\text { with all } \\
\text { three goals }\end{array}$ \\
\hline $\begin{array}{l}\text { Clinical } \\
\text { Decisions } \\
\text { Unit } \\
\text { (CDU) }\end{array}$ & $\begin{array}{l}56 \\
(75 \%)\end{array}$ & $\begin{array}{l}42 \\
(56 \%)\end{array}$ & $\begin{array}{l}47 \\
(63 \%) \\
1 \text { hour }\end{array}$ & $\begin{array}{l}22 \\
(30 \%)\end{array}$ \\
\hline $\begin{array}{l}\text { Accident } \\
\text { \& Emer- } \\
\text { gency } \\
\text { (A\&E) }\end{array}$ & $\begin{array}{l}113 \\
(92 \%)\end{array}$ & $\begin{array}{l}104 \\
(84 \%)\end{array}$ & $\begin{array}{l}98 \\
(80 \%) \\
3 \text { hours }\end{array}$ & $\begin{array}{l}78 \\
(63 \%)\end{array}$ \\
\hline $\begin{array}{l}\text { Total } \\
\text { I98 }\end{array}$ & $\begin{array}{l}169 \\
(\mathbf{8 5} \%)\end{array}$ & $\begin{array}{l}\mathbf{1 4 6} \\
\mathbf{( 7 4 \% )}\end{array}$ & $\begin{array}{l}\mathbf{1 4 5} \\
\mathbf{( 7 4 \% )}\end{array}$ & $\begin{array}{l}\mathbf{1 0 0} \\
\mathbf{( 5 1 \% )}\end{array}$ \\
\hline
\end{tabular}

had lactate measured, 47 (63\%) received antibiotics within one hour and 22 (30\%) individuals achieved compliance with all three targets. In the emergency department, 123 septic patients were identified, and of these, II 3 (92\%) had blood cultures taken, 104 (84\%) had lactate measured, $98(80 \%)$ were given antibiotics within three hours and $78(63 \%)$ individuals achieved compliance with all three targets. We estimate that this represented $3 \%$ of medical admissions, based on the annual rate of admissions through this unit. Results are summarised in Table I.

A subgroup of patients suffered from severe sepsis. Fourteen of these patients were identified in CDU. Of these, I I (79\%) had blood cultures taken, nine (64\%) had lactate measured, eight (57\%) received antibiotics within one hour and 10 (7I\%) received appropriate fluids. Five (36\%) achieved compliance with all four targets. Twentynine patients in the emergency medicine department suffered from severe sepsis, of which 28 (96\%) had blood cultures taken, 29 (100\%) had lactate measured, 26 (89\%) received antibiotics within three hours, 26 (89\%) received appropriate fluids and 28 (65\%) individuals complied with all four targets. Two patients in the emergency medicine department remained hypotensive

\section{TABLE 2 Results for subgroup with severe sepsis}

\begin{tabular}{|c|c|c|c|c|}
\hline & $\begin{array}{l}\text { Blood } \\
\text { cultures } \\
\text { taken }\end{array}$ & $\begin{array}{l}\text { Lactate } \\
\text { levels } \\
\text { measured }\end{array}$ & $\begin{array}{l}\text { Time } \\
\text { to anti- } \\
\text { biotics }\end{array}$ & $\begin{array}{l}\text { Compliance } \\
\text { with all } \\
\text { four goals }\end{array}$ \\
\hline $\begin{array}{l}\text { Clinical } \\
\text { Decisions } \\
\text { Unit } \\
\text { (CDU) }\end{array}$ & $\begin{array}{l}11 \\
\text { (79\%) }\end{array}$ & $\begin{array}{l}9 \\
(64 \%)\end{array}$ & $\begin{array}{l}8 \\
(57 \%) \\
\text { I hour }\end{array}$ & $\begin{array}{l}5 \\
(36 \%)\end{array}$ \\
\hline $\begin{array}{l}\text { Accident } \\
\text { \& Emer- } \\
\text { gency } \\
\text { (A\&E) }\end{array}$ & $\begin{array}{l}28 \\
(96 \%)\end{array}$ & $\begin{array}{l}29 \\
(100 \%)\end{array}$ & $\begin{array}{l}26 \\
(89 \%) \\
3 \text { hours }\end{array}$ & $\begin{array}{l}23 \\
(79 \%)\end{array}$ \\
\hline $\begin{array}{l}\text { Total } \\
43\end{array}$ & $\begin{array}{l}39 \\
(91 \%)\end{array}$ & $\begin{array}{l}38 \\
(88 \%)\end{array}$ & $\begin{array}{l}34 \\
(79 \%)\end{array}$ & $\begin{array}{l}28 \\
(65 \%)\end{array}$ \\
\hline
\end{tabular}

after fluid bolus. Both had central venous lines inserted before transfer to the intensive care unit. Their management in the ICU is outside the scope of this audit. Results are summarised in Table 2.

The Preston audit identified 30 patients with sepsis, of which II had severe sepsis. Of these, one patient had the local equivalent of a sepsis sticker inserted in their notes. The remaining patients met the diagnostic criteria for sepsis but did not have a diagnosis of sepsis syndrome recorded at the time of their assessment.

Fifteen $(50 \%)$ of the patients with sepsis $(n=30)$ had blood cultures taken. Ten (30\%) had lactate measured. Six $(20 \%)$ received antibiotics within one hour of admission. Compliance with all elements of the pathway was not achieved in any patient.

\section{DISCUSSION}

We believe we were successful in generating a culture where the identification and early treatment of sepsis was seen as a high priority. The results of our audit demonstrate that a reasonable degree of compliance with elements of the Surviving Sepsis bundles can be achieved in a district general hospital. We are not aware of any similar prospective observations in other hospitals. Our outcomes compare favourably however to retrospective data published from other hospitals, which had not undertaken similar educational campaigns at the time of their study. ${ }^{9-10}$

This paper reports on a simple survey of compliance with care guidelines in patients identified as having sepsis, following our campaign to educate and therefore increase implementation. It might have been strengthened by comparison to compliance data from before our campaign. Our Trust implemented this campaign because our hospital's mortality data showed a high patient mortality rate within 48 hours of admission. A notes review of deaths in this category identified sepsis as a major contributor to these deaths and one with a clear potential for reduction. A review of the level of awareness of sepsis guidelines among junior doctors showed poor levels of knowledge. The decision was therefore made to implement our campaign as soon as possible. It was considered inappropriate to wait while pre-intervention data were gathered.

We did not gather mortality data on the patients involved in this study, however the Trust's risk-adjusted mortality index was monitored by an independent company from 2008 to 2010 , and it fell from 103 to 79 during this period." We cannot say to what extent the Surviving Sepsis campaign contributed to this reduction, but it was one of three major campaigns underway during this period - the others related to reductions in hospital acquired infections and venous thromboembolism. 


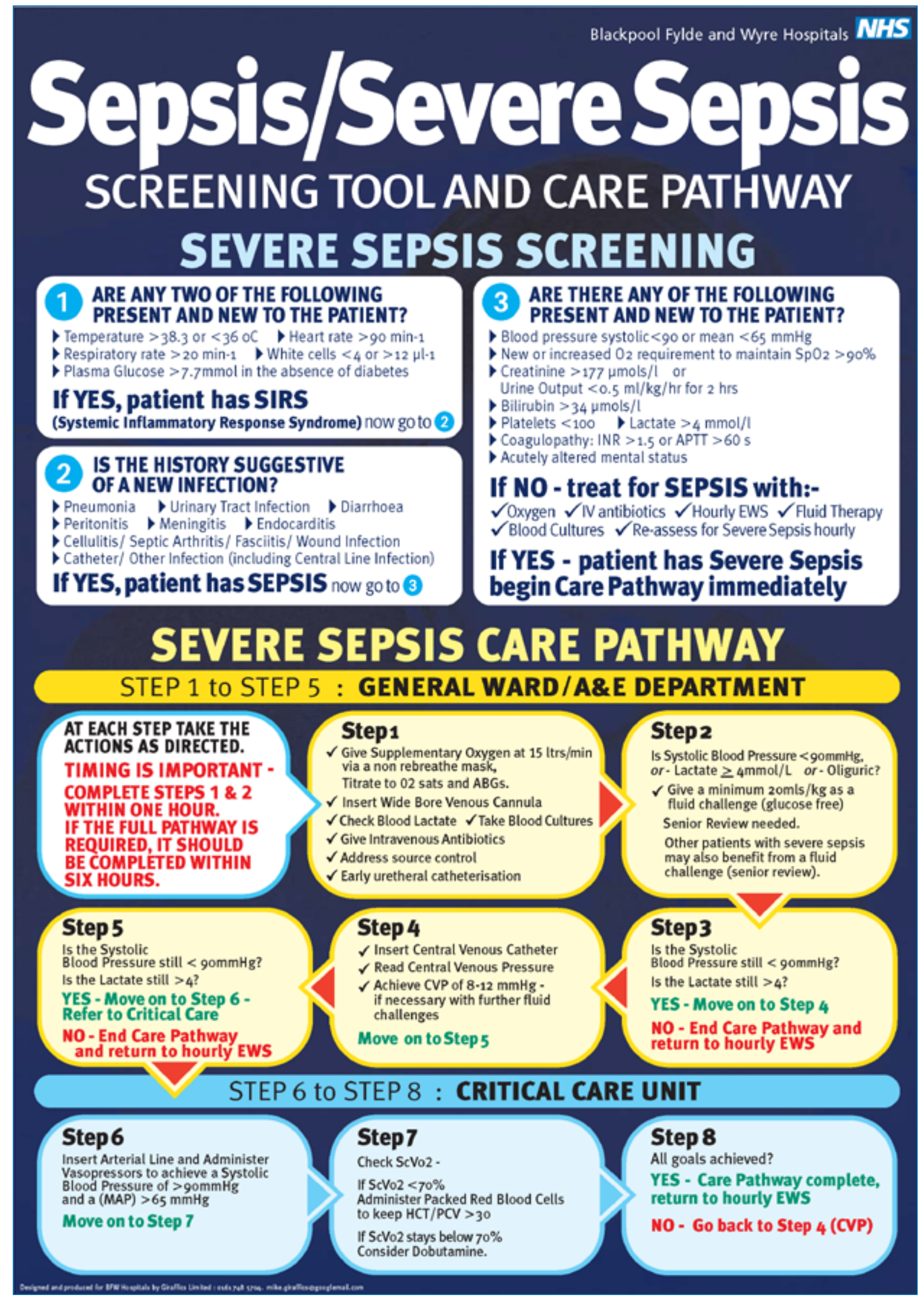

FIGURE 2 Surviving sepsis poster as displayed in the emergency department. Reproduced with kind permission of Blackpool Teaching Hospitals NHS Foundation Trust. 
Our study was aimed solely at implementing good sepsis care in the first six hours of patient admission. Most microbiological tests are not available within this timeframe and we did not require definitive evidence of infection for entry into our study. It is therefore possible that some patients recorded were not suffering from infection. We believe that this is legitimate however, as Surviving Sepsis guidelines are based on the knowledge that delay to treatment leads to higher mortality rates. As definitive microbiological diagnoses are not available within the guideline window it is essential that a clinical, syndromic definition be used. Indeed that is the key concept at the heart of the guidelines.

The use of a $20 \mathrm{ml} / \mathrm{kg}$ fluid challenge in cases of severe sepsis might be considered an aggressive treatment. We would emphasise that in order to be defined as having severe sepsis a patient had to have clear evidence of hypoperfusion. A patient's comorbidities might lead to such a bolus being considered inappropriate. As with all guidelines, Surviving Sepsis goals are not intended to replace clinical judgement. If a doctor opted not to give the full $20 \mathrm{ml} / \mathrm{kg}$ bolus and documented a valid reason, we included that patient as having received an appropriate fluid challenge and thus having complied with guidelines.

We did not achieve 100\% compliance with guidelines. There are a number of possible reasons for this. Our decision to aim for compliance with goals one to three of the Severe Sepsis treatment bundle in all septic patients was intended to ensure prompt identification of severely septic patients and to prevent progression of patients with sepsis to severe sepsis. This approach was labour intensive however, and may have contributed to a reduction in compliance.

We also note that our study design looked at management of patients once sepsis was identified. It does not tell us how successful we were at identifying septic patients at triage. The retrospective audit of septic patients at Preston found only one patient who had the equivalent sepsis form placed in their notes. At Blackpool, 198 septic patients were identified over a five-month period, suggesting the use of surviving sepsis teams was associated with a higher rate of sepsis identification.

The differences in methodology between these two audits mean that any comparisons must be made with caution. Ideally we would have included data from Blackpool prior to our interventions. As this was not possible, we have included the data from Preston as a representation of sepsis management at a comparable local hospital (Table 3). While guideline compliance at Blackpool was not ideal, better compliance with guidelines was achieved in the Blackpool group, where sepsis had been identified and a sepsis sticker utilised, than in the Preston group, composed almost entirely of cases where sepsis forms were not used.
TABLE 3 Results of retrospective sepsis audit at Preston Royal Hospital

\begin{tabular}{|l|l|l|l|l|}
\hline & $\begin{array}{l}\text { Blood } \\
\text { cultures } \\
\text { taken }\end{array}$ & $\begin{array}{l}\text { Lactate } \\
\text { levels } \\
\text { measured }\end{array}$ & $\begin{array}{l}\text { Time } \\
\text { to anti- } \\
\text { biotics }\end{array}$ & $\begin{array}{l}\text { Compliance } \\
\text { with all } \\
\text { three goals }\end{array}$ \\
\hline $\begin{array}{l}\text { Preston } \\
\text { Royal } \\
\text { Hospital } \\
(n=30)\end{array}$ & $\begin{array}{l}15 \\
(50 \%)\end{array}$ & $\begin{array}{l}10 \\
(30 \%)\end{array}$ & $\begin{array}{l}6 \\
(20 \%)\end{array}$ & $\begin{array}{l}0 \\
(0 \%)\end{array}$ \\
\hline
\end{tabular}

Compliance was better in A\&E than in CDU.The campaign in A\&E was being led by a doctor who worked full-time in the department, with the constant support of an identified lead sepsis nurse. In CDU, as a result of the on-call rota system, the doctor leading the campaign was only in the unit when on-call. The nurse appointed to lead implementation in CDU left the department during the course of the campaign. There appears to be an association between the level of involvement of senior full-time members of staff in a unit and good compliance rates.

We are continuing our education programme and hope to improve our compliance rate further. We are also rolling out the programme to other acute admission units in our hospital, including surgical wards and the haematology department. As all junior doctors rotate through these acute areas we hope they will take the information about the identification and treatment of sepsis they gain there to other parts of the hospital when they move on.

There is ongoing improvement work being undertaken in the Trust with the active participation of senior level nursing staff and medical staff of all grades. The sepsis flowchart has been incorporated directly into the observation charts used for all patients. In addition, the medical records system is being computerised, which we hope will result in an inbuilt systems process, which will automatically highlight the presence of SIRS whenever criteria are met. We expect that together these interventions will lead to improved sepsis care throughout the Trust.

We have shown that good compliance with surviving sepsis guidelines can be achieved - even in the challenging real world environment of a district general hospital. We will repeat our audits of sepsis management and continue to revise our practise until full implementation is achieved. The changes we have introduced required very little in the way of financial support. Our posters may require adaption to local circumstances (e.g. availability of central line monitoring on CDU and thus timing of referral to ICU). Nonetheless we believe that our programme should be transferable to almost any acute hospital, even in an age of financial austerity. We believe this represents possibly one of the easiest and most cost-effective ways of reducing inpatient mortality rates. 


\section{REFERENCES}

I Rivers E, Nguyen B, Havstad S et al. Early goal-directed therapy in the treatment of severe sepsis and septic shock. N EnglJ Med 200 I; 345: I368-77. http://dx.doi.org//0.1056/NEJMoa0I0307

2 Natanson C, Esposito CJ, Banks SM et al. The sirens song of confirmatory sepsis trials: selection bias and sampling error. Crit Care Med 1998; 26:1927-3I. http://dx.doi.org/I0.1097/000032461998I2000-0000I

3 Bernard GR, Vincent JL, Laterre PF et al. Efficacy and safety of recombinant human activated protein $C$ for severe sepsis. $N$ Engl J Med 200I; 344:699-709. http://dx.doi.org/I0.1056/ NEJM200I0308344I00I

4 Bone RC, Balk RA, Cerra FB. Definitions for sepsis and organ failure and guidelines for the use of innovative therapies in sepsis. The ACCP/SCCM consensus conference committee. American College of Chest Physicians/Society of Critical Care Medicine. Chest 1992; 101:I644-55. http://dx.doi.org/I0.I378/chest.I0I.6.1644

5 Organisation for Economic Co-operation and Development. Health Report at a glance 2009 [Internet]. Paris: OECD; 2009 [cited 201। OCt 19]. Available at: http://www.oecd-ilibrary.org/social-issuesmigration-health/health-at-a-glance-2009_health_glance-2009-en

6 Kanji S, Devlin JW, Piekos KA et al. Recombinant activated human protein C, drotrecogin alfa (activated): a novel therapy for severe sepsis. Pharmacotherapy 200 I; 21:I389-402. http://dx.doi.org/I0.1592/ phco.2I.I7.I389.344I7
7 Dellinger RP, Carlet JM, Masur $\mathrm{H}$ et al. Surviving sepsis campaign management guidelines committee:Surviving sepsis campaign guidelines for management of severe sepsis and septic shock. Crit Care Med 2004 32: 858-73. http://dx.doi.org/I0.1097/0I.CCM.0000 I I73 I7.18092.E4

8 Dellinger RP, Levy MM, Carlet JM et al. Surviving sepsis campaign: international guidelines for management of severe sepsis and septic shock: 2008. Crit Care Med 2008; 36:296-327. http://dx.doi. org/I0.1097/0I.CCM.0000298I58.12101.4I

9. Mitchell $M$, Levy $R$, Dellinger $P$ et al. The Surviving Sepsis Campaign: results of an international guideline-based performance improvement program targeting severe sepsis. Intensive Care Med 2010; 36: 222-31. http://dx.doi.org/I0.1007/s00I34-009-1738-3

10 Simmonds $M$, Hutchison $A$, Chikhani $M$ et al. Surviving sepsis beyond intensive care: a retrospective cohort study of compliance with the international guidelines. Intensive Care Med 2008; 9:124-27.

II Blackpool, Fylde and Wyre Hospitals NHS Foundation Trust. [Internet] Annual Report and Accounts April I 2009 to March 3I 2010 [cited 201I Sept 29]. Available from: http://www.bfwh.nhs uk/departments/comms/docs/publications/annual_reports/ Blackpool\%20Full\%208\%207\%20I0.pdf

\section{INVITATION TO SUBMIT PAPERS}

We would like to extend an invitation to all readers of The Journal of the Royal College of Physicians of Edinburgh to contribute original material, especially to the clinical section. The JRCPE is a peer-reviewed journal with a circulation of 8,000 . It is also available open access online. Its aim is to publish a range of clinical, educational and historical material of cross-specialty interest to the College's international membership.

The JRCPE is currently indexed in Medline, Embase, Google Scholar and the Directory of Open Access Journals. The editorial team is keen to continue to improve both the quality of content and its relevance to clinical practice for Fellows and Members. All papers are subject to peer review and our turnaround time for a decision averages only eight weeks.

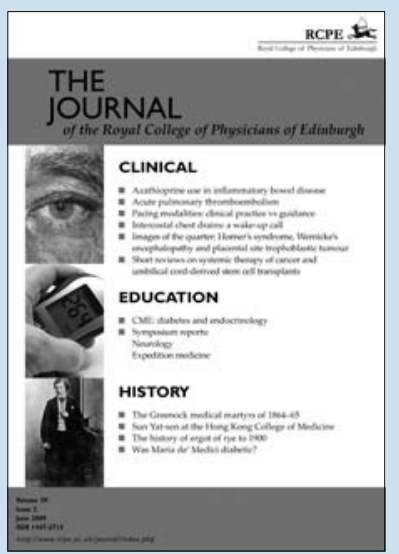

We would be pleased to consider submissions based on original clinical research, including pilot studies. The JRCPE is a particularly good forum for research performed by junior doctors under consultant supervision. We would also consider clinical audits where the 'loop has been closed' and a demonstrable clinical benefit has resulted.

For further information about submissions, please visit: http://www.rcpe.ac.uk/journal/contributers.php or e-mail editorial@rcpe.ac.uk.Thank you for your interest in the College's journal.

The editorial team,

The Journal of the Royal College of Physicians of Edinburgh 